\title{
Sophisticated Glass Tapes for Fabrication of Composites *
}

\author{
Mohanapriya Venkataraman ${ }^{\text {a,* }}$, Jiří Militkýa ${ }^{\mathrm{a}}$, Roman Pulíček ${ }^{\mathrm{a}}$, \\ Jana Novotnáa ${ }^{\mathrm{a}}$, Alžbeta Samkováa ${ }^{\mathrm{a}}$, Karolína Voleskáb, ${ }^{\mathrm{b}}$ Pavel Srb ${ }^{\mathrm{c}}$, \\ Vijay Baheti ${ }^{a}$, Rajesh Mishra ${ }^{a}$ \\ ${ }^{a}$ Technical University of Liberec, Faculty of Textile Engineering, Department of Material Engineering, \\ Liberec 46117, Czech Republic \\ ${ }^{\mathrm{b}}$ Technical University of Liberec, Department of the Preparation and Analysis of Nanostructures, \\ Institute for Nanomaterials, Advanced Technology and Innovations, Czech Republic \\ ${ }^{\mathrm{c}}$ Technical University of Liberec, Faculty of Mechanical Engineering, Department of the Design of \\ Machine Elements and Mechanisms, Czech Republic
}

\begin{abstract}
The mechanical properties of fabrics derived from glass tows are excellent. They can be used for reinforcement of composites. In this work, glass fiber based stabilized hybrid composite tapes (SHCT) containing special types of resins which could be used for preparation of composites using precise winding technique was prepared. The resins were loaded by suitable types of nanoparticles that would enhance mechanical properties. Detailed investigation of tensile forces like breaking force, deformation at break and initial modulus was conducted. The results showed a significant difference between the samples. This research achieved loading of resins without its penetration into the winded structure through tight and complicated arrangement of fibrous phase. The tapes were found to be durable that enables their long-term storage and their sustained fit-to-use after extended storage times.
\end{abstract}

Keywords: Hybrid Tapes; Tensile Properties; Precise Winding; Composites; Epoxy Resin

\section{Introduction}

The properties that glass fibers exhibit are their nonflammability, strength, abrasion resistance, cost effective processing and reasonable price. This makes them excellent candidates for Textile applications. Some of the disadvantages are sensitivity to strong alkalis, surface corrosion, fragility and relatively hard processability [1-7]. These fabrics are produced using multifilament yarns. The compactness and improvement of strength and evenness is achieved by gluing them together (roving yarn) into tape shapes (tows) $[8,9]$. Composites are made of multifilaments. Low bending

${ }^{\star}$ Project supported by Sophisticated hybrid tapes for fabrication of composites by precise winding (Project No. TJ01000292, 14014/136).

* Corresponding author.

Email address: mohanapriya.venkataraman@tul.cz (Mohanapriya Venkataraman). 
stiffness is maintained by a combination of filaments of low fineness below $10 \mu \mathrm{m}$ diameter. The cross-sectional fibers may range from anything between 1000 to 24000 . The circular crosssection and density are directly proportional to number of twists and inversely proportional to the initial modulus and yarn strength. Due to the increased density, resin does not penetrate easily. Prepregs can be manufactured using rovings with twists of less than $50 \mathrm{curls} / \mathrm{m}$ which have an oval cross section and decreasing porosity from edge to the centers. Spread tow tapes width may be up to 3 times the diameter of the original multifilament. When the individual filaments are very closely arranged, they behave like a bunch of identical long parallel threads. This arrangement leverages the strength of individual filaments and influences the thickness and density [10-13]. However, cohesion and resin saturation are affected by long storage. Composite materials' mechanical properties are sometimes compromised due to usage of roving affected by uneven disconnection of fibers under high speeds of production and spinning. Due to this reason, only a percentage of fibers can be completely turned off during the preparation of the prepreg when the composite is loaded. This paper deals with the preparation of stabilized hybrid composite tapes (SHCT) with an optimally arranged resin-bonded fibrous phase and surface nanoparticles with which composites can be made by precision robotic winding. The mechanical properties (breaking force, deformation at break, initial modulus) of stabilized hybrid composite tapes (SHCT) was studied.

\section{Materials and Method}

The stabilized hybrid composite tape SHCT (Fig. 1) consists an expanded tape of a glass uncoated multifilament cable (E-glass 1310 fibers) parallelized to the direction of the belt axis. The strength of the epoxy-free tape (sample 1) was 285.6 $\mathrm{N}\left(\mathrm{s}^{*}=14.61\right)$, the strength of the fibers was 30.65 $\mathrm{cN}\left(\mathrm{s}^{*}=2.09\right)$ and the number of fibers in the tape were estimated as 922 . The parameters of the fibres are provided in Table 1.

Table 1: Fibre Parameters

\begin{tabular}{lccc}
\hline Parameter & Confidence Interval (C.I)* & Lower Limit (LL)* & Upper Limit (UL)* \\
\hline Fineness (dtex) & 3.16 & 2.60 & 3.72 \\
Strength (cN) & 30.64 & 26.29 & 35.0 \\
Deformation at break (\%) & 6.72 & 6.07 & 7.35 \\
Initial modulus (GPa) & 26.12 & 17.30 & 34.95 \\
\hline
\end{tabular}

Special catalysts in Epoxy type resins extends storage duration and subsequent heat curing. Grinding activated fumed F-type fly ash supplied by SILO, Pilsen Czech Republic, at 3\% concentration and mechanically activated by Fritsch pulversisette 7 planetary ball mill, was found to improve most of the mechanical properties of the matrix. Glass filaments of 600 Tex, thickness of $2.15 \mathrm{~mm}$ and of a fiber content of 0.34 were used as textile reinforcement. CHS-EPOXY 200 $\mathrm{V}$ with a catalyst were purchased from Spolchemie and Chemex, Czech Republic and the mixing ratio was 100:27 by weight. First, hardener was mixed with fillers, and then the resultant solution was mixed with epoxy by using a magnetic stirrer for 5 minutes. A homogenous mixture was obtained by mixing fly ash particles with epoxy resin at room temperature. The composite was cured in an oven at $120{ }^{\circ} \mathrm{C}$ and $50 \mathrm{kPa}$ for 30 minutes. The samples are described in Table 2 . 
Table 2: Sample Description

\begin{tabular}{ccc}
\hline Sample number & Type of resin & Fillers \\
\hline $1322 / 1$ & Epoxy resin dispersion CHS-EPOXY 200 V 55 with catalyst & $1 \%$ fly ash \\
$1322 / 2$ & Epoxy resin dispersion CHS-EPOXY 200 V 55 with catalyst & $2 \%$ fly ash \\
$1322 / 3$ & Epoxy resin dispersion CHS-EPOXY 200 V 55 with catalyst & $3 \%$ fly ash \\
$1322 / 4$ & Epoxy resin dispersion CHS-EPOXY 200 V 55 with catalyst & $4 \%$ fly ash \\
$1322 / 5$ & Epoxy resin dispersion CHS-EPOXY 200 V 55 with catalyst & $5 \%$ fly ash \\
M130 & Methyl silicon resin, Polymerized at ambient temperature & \\
ELX & Water emulsion of M130, Polymerized at ambient temperature \\
DLX & Water emulsion of polysiloxane and silane, polymerised at ambient temperature \\
$200 x$ & Methylsilicon resin with toluene, polymerised at temperature of $200{ }^{\circ} \mathrm{C}$ & \\
$150 \mathrm{x}$ & Methylsilicon resin, polymerised at temperature of $200{ }^{\circ} \mathrm{C}$ & \\
\hline
\end{tabular}

Using the pilot plant built by Večerník s.r.o. company, prepregs made of glass roving in the form of thin endless tapes were produced. This device controls the speed of initial unwinding of roving and final winding of finished prepreg. It also maintains a constant strain of roving. The overall path of roving before the wrap of the prepreg is about $15 \mathrm{~m}$. In the first part, roving passes through the smooth steel rod system to separate individual fibers. The pull on the roving facilitates constant disconnection of the individual fibres. The roving was made from a mixture of acrylate polymers and epoxysilane suitable for epoxy matrices. The major aim of this research was to achieve a homogenous arrangement of the individual fibers with parallel arrangement that at least ensures approximation to the theoretical value of the glass fiber strength. This was expected to improve the mechanical properties of composites made from the prepregs. To ensure sufficient epoxy matrix content, three epoxy dispersion-based coating stations were used in the line. After the last coating of the epoxy dispersion with the catalyst, a cross-winding was performed on a paper roll manually. The cross section and SEM image of hybrid tapes shown in Fig. 1.
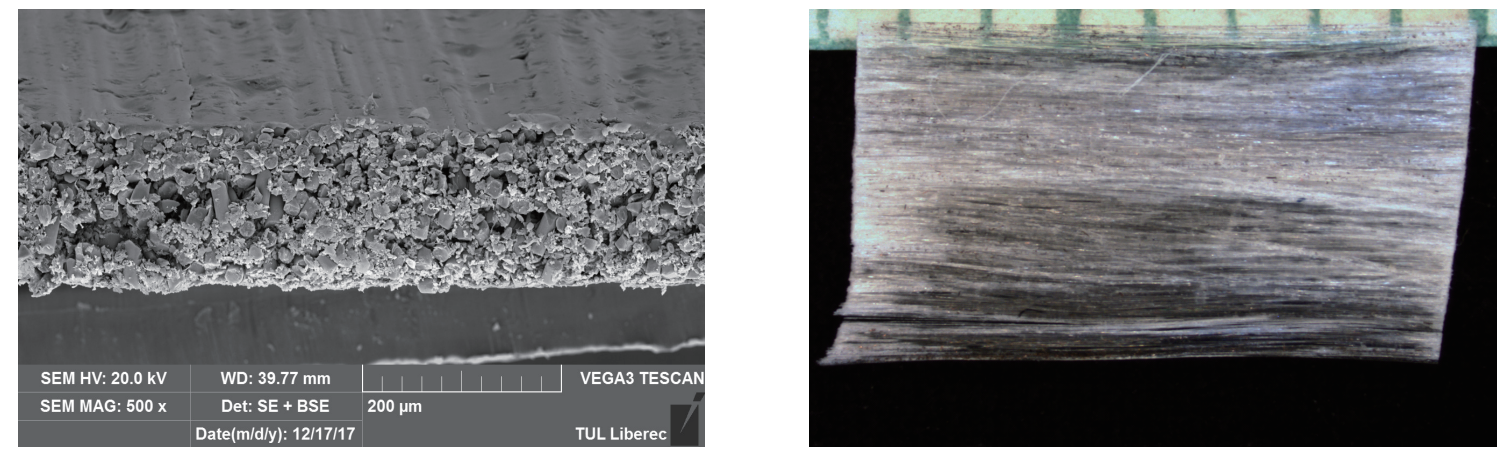

Fig. 1: Cross-section and view of a stabilized hybrid nano composite tape

The tensile properties were measured by $1000 \mathrm{~N}$ (Instron instrument) head with pneumatic jaws and rubber, a clamping length of $200 \mathrm{~mm}$, a jaw velocity of $50 \mathrm{~mm} / \mathrm{min}$, i.e. a strain rate of $0.25 / \mathrm{min}$, a tape thickness of $0.16 \mathrm{~mm}$ (differences without epoxy) and a width of $4 \mathrm{~mm}$. Dynamical mechanical analyzer DMA DX04T was used for mechanical analysis. Fiber properties were measured in Vibrodyn 400 instrument. The weathering test was done in Atlas weathering instrument at 80 deg C 65\% RH for 240 hours in VUTS, Czech Republic. 


\section{Results and Discussion}

The initial modulus in MPa applies to all samples on a constant surface of $4 \times 0.16=0.64 \mathrm{~mm}^{2}$. Figures 2 to 5 show the mechanical characteristics of the samples. The results showed a significant difference between the samples. The glass tapes coated with epoxy resin had the highest values of strength, deformation at break and initial modulus. The results showed variable values for glass with epoxy dissolved in acetone which indicated imperfect removal of the epoxy. Values in the graph specifies the $95 \%$ confidence intervals of mean values of Maximum force, deformation at break and modulus.

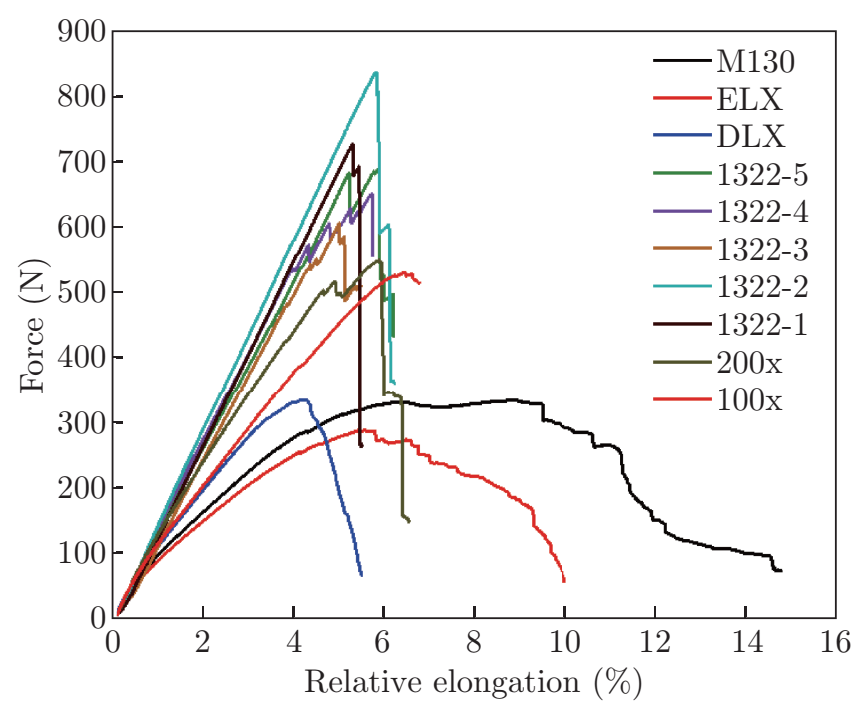

Fig. 2: Relative elongation of glass tapes

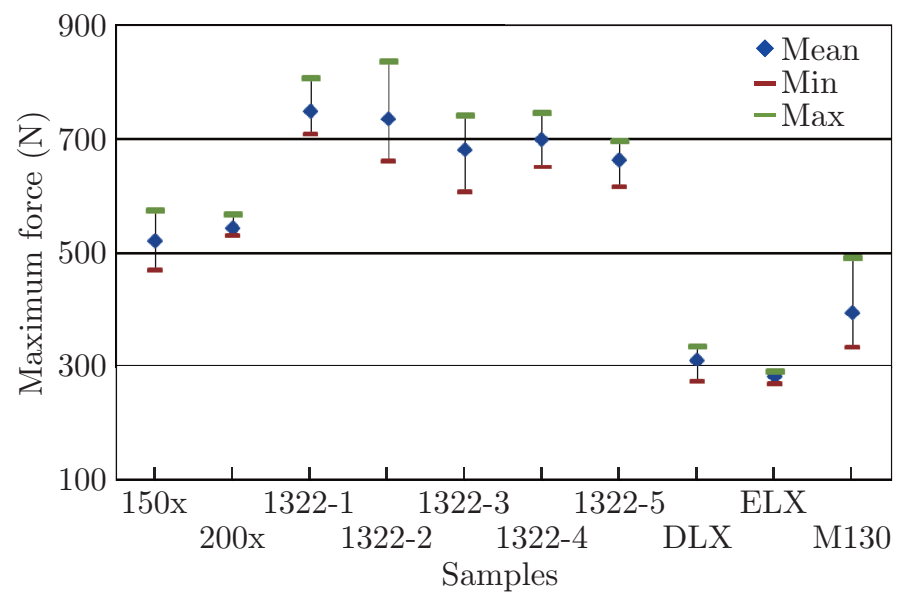

Fig. 3: Breaking force of glass tapes

Composite specimens containing activated fly ash particles containing $1 \%$ by weight exhibited the greatest improvement in bending properties (the bending modulus increased from 87.55 to $\mathrm{GPa}$ of $124.35 \mathrm{GPa}$ and the bending strength increased from $621.63 \mathrm{MPa}$ to $634.20 \mathrm{MPa}$.). The addition of activated fly ash in 1, 3 and $5 \%$ by weight, the bending modulus changed by $0.71 \%$, $42.50 \%$ and $58.93 \%$ and bending strengths of $12.05 \%, 33.58 \%$ and $47.35 \%$ relative to ash-free 
samples. The agglomeration of fly ash particles is likely to increase at higher concentrations in the composites. For composite samples containing activated fly ash particles, an improvement in tensile characteristics up to $3 \%$ by weight of fly ashes was found.

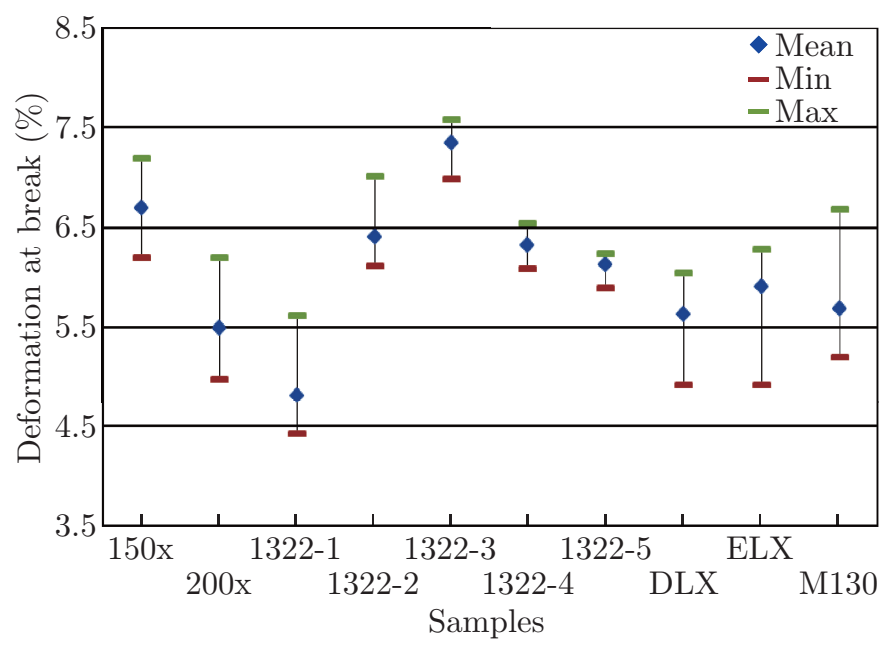

Fig. 4: Deformation at break of glass tapes

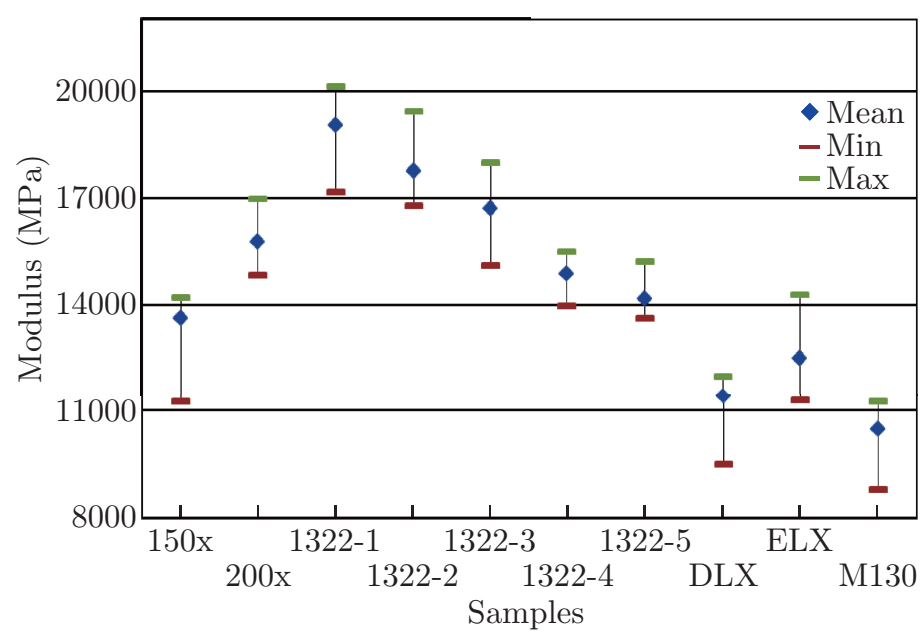

Fig. 5: Modulus of glass tapes

There is a significant increase in the modulus and a slight increase in tensile strength compared to ash-free composites. A maximum increase of the initial modulus from $27.32 \mathrm{GPa}$ (ashless composite) to $48.22 \mathrm{GPa}$ (a composite containing $3 \%$ by weight of ground fly ash) was achieved. Composite samples filled with 1,2, 3, 4 and $5 \%$ by weight of ground fly ash had an impact strength increase of $17.20 \%, 60.71 \%, 31.18 \%, 23.62 \%$ and $18.86 \%$. However, the composite filled with original fly ash exhibited only $5.64 \% 10.27 \%, 13.54 \%, 11.22 \%$ and $1.57 \%$ increase in impact strength compared to ash-free samples.

The dynamic elastic modulus of ash-filled composites improves over the entire temperature range compared to the uncompleted composite. A significant effect of the ash refinement by grinding on the dynamic elastic module is demonstrated. The maximum improvement was observed for a $10 \%$ concentration of softened ash where the dynamic elastic modulus was increased from 18.1 to $34.8 \mathrm{GPa}$ at $60{ }^{\circ} \mathrm{C}$. For composites filled with refined ash at concentrations of 1,2 , 


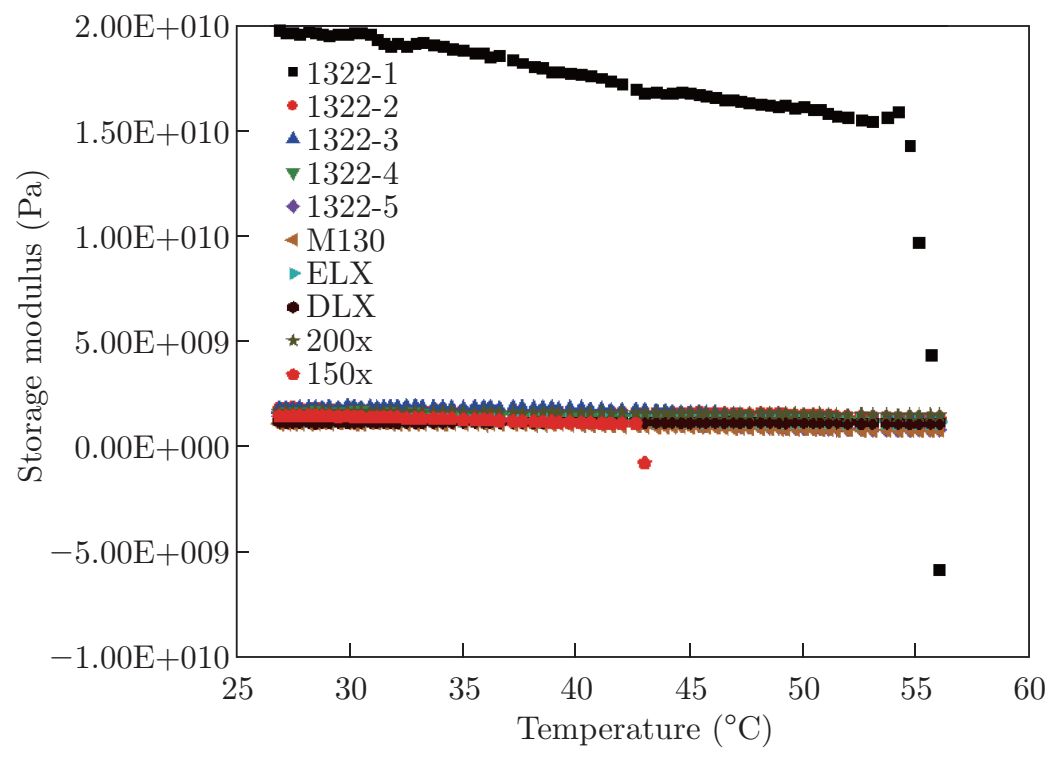

Fig. 6: Storage modulus of glass tapes

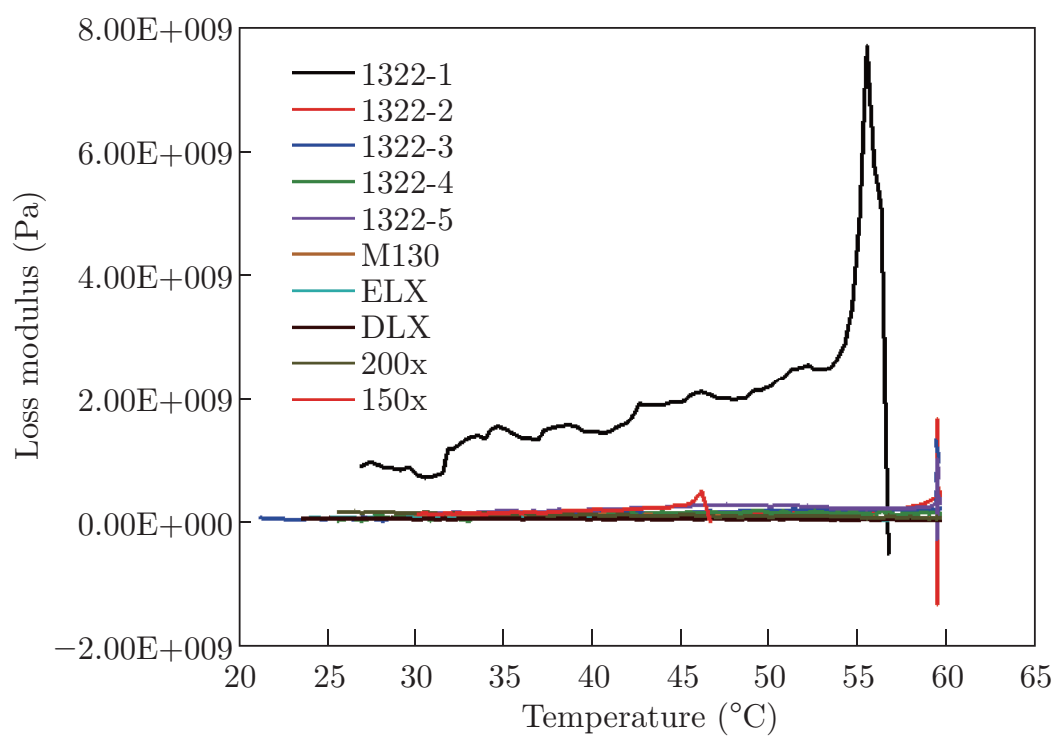

Fig. 7: Loss modulus of glass tapes

3,4 and $5 \%$ to $30.38 \%, 33.70 \%, 48.61 \%, 32.38 \%$ and $92.26 \%$ of module growth. In the case of a composite with only methyl silicone resin, the dynamic elastic modulus increased by $50.27 \%$, $22.65 \%, 45.85 \%, 30.54 \%$ and $29.83 \%$ at $60{ }^{\circ} \mathrm{C}$, depending on its concentration.

Mechanical tests and dynamic mechanical analysis were used to select a suitable filler and its concentration. The loss of mechanical properties was not significant for the samples before and after weathering. Based on these tests, $3 \%$ by weight of fly ash particles was chosen as optimal with respect to the combination of improvement of mechanical properties ease of preparation and possible health aspects. While it is not the best in terms of the dynamic elastic modulus but with the inclusion of static mechanical characteristics and impact characteristics as a suitable compromise. 


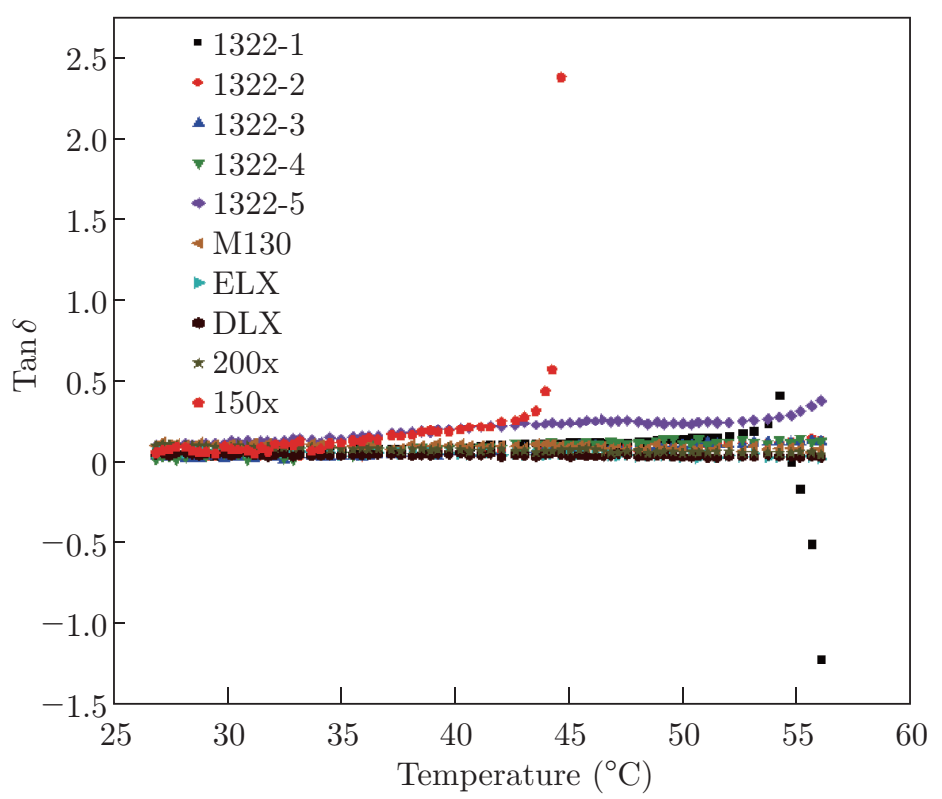

Fig. 8: Tan delta plot of glass tapes

\section{Conclusion}

This research resulted in development of advanced glass fiber based tapes containing special types of resins in pre-condensate form used for composites preparation by precise winding. The major benefit was avoidance of resin penetration into winded structure through optimization of tape geometry and composition according to the requirement of precise winding, maximum use of tow filaments strength and enhanced durability for long term storage of tapes. The maximum force, deformation at break, modulus was enhanced by adding nanoparticles in the resin. This resulted in significant difference between the samples. It was discovered that resin containing ground fly ash particles increased the strength and SHCT modulus significantly over the spread of the glass tape. The weathering tests revealed that mechanical properties were not compromised before and after weathering. The durability tests confirmed the sophisticated glass tapes for fabrication of composites were fit for longer storage life without loss of mechanical properties over extended storage times.

\section{Acknowledgement}

This work was supported by the project "Sophisticated hybrid tapes for fabrication of composites by precise winding" [Project no: TJ01000292, 14014/136].

\section{References}

[1] Artemenko SE. Polymer composite materials made from carbon, basalt, and glass fibers. Structure and properties. Fibre Chem: 2003; 3: 226-229.

[2] Artemenko SE, Kadykova Yu A. Polymer composite materials based on carbon, basalt, and glass fibers. Fibre Chem: 2008; 1: 37-39. 
[3] Singha KA. Short Review on Basalt Fibre. Int J Text Sci: 2012; 4: 19-28.

[4] Cerny M, Glogar P, Golias V, Hruska J, Jakes P, Sucharda Z, Vavrova I. Comparison of mechanical properties and structural changes of continuous basalt and glass fibers at elevated temperatures. Ceramics - Silikáty: 2007; 2: 82-88.

[5] Information on http://www.ru.is/media/sel-greinar/Basalt-paper-HO_ETh.pdf.

[6] Kovačević S, Ujevi?D, Brnada S, Brlobašić Šajatović B. Structural Multi-layered Composite Textiles Materials: Textile Science and Economy III. Ed. Pavlovi?M, Milan, Zrenjanin, University of Novi Sad., Technical faculty: 2011; 50-67.

[7] Šomodi Ž, Kovačević S, Dimitrovski K. Fabric Distortion After Weaving-An Approximate Theoretical Model. 5th International Textile, Clothing and Design Conference 2010-Magic World of Textile. Ed. Dragčević Z, Hursa Šajatović A, Vujasinović E, Dubrovnik, Faculty of Textile Technology. Croatia, 3-6 October 2010, 729-734.

[8] Skoko M. Investigation of the Properties with Multiaxial Strengths and Deformations of Coated Fabrics. Tekstil 1998; 7: 339-344.

[9] Behera BK, Hari PK. Woven textile structure: Theory and applications. Ed. Cornwall, UK: Woodhead publishing series in textiles, 2010.

[10] Ohlsson F. Weight reduction by optimized reinforcement structures, kap. 8 v knize Njuguna J. ed.: Lightweight Composite Structures in Transport Design, Manufacturing, Analysis and Performance Elsevier Ltd., Cambridge 2016.

[11] Cornelissen B. Akkerman R. Towards Modeling of the Frictional Behavior of Deforming Fibrous Tows: A Geometrical Approach, kap. v knize Binetruy Ch., Boussu F. eds: Recent Advances in Textile Composites, DEStech Publications, Inc., Lancaster 2010.

[12] Information on http://www.kraftstore.top/index.php?main_page=product_info\&products_id=8319.

[13] EL-Dessouky H.M. Ultra-light weight thermoplastic composites: tow spreading technology. ECCM15 - 15th European Conference on Composite Materials, Venice, Italy, 24-28 June 2012. 